\title{
Machine-learning-based calving prediction from activity, lying, and ruminating behaviors in dairy cattle
}

\author{
M. R. Borchers, ${ }^{*}$ Y. M. Chang,† K. L. Proudfoot, $\ddagger$ B. A. Wadsworth, ${ }^{*}$ A. E. Stone, ${ }^{*}$ and J. M. Bewley ${ }^{* 1}$ \\ *Department of Animal and Food Sciences, University of Kentucky, Lexington 40546 \\ †Research Support Office, Royal Veterinary College, University of London, NW1 0TU, United Kingdom \\ ‡Department of Veterinary Preventive Medicine, The Ohio State University, Columbus 43210
}

\section{ABSTRACT}

The objective of this study was to use automated activity, lying, and rumination monitors to characterize prepartum behavior and predict calving in dairy cattle. Data were collected from 20 primiparous and 33 multiparous Holstein dairy cattle from September 2011 to May 2013 at the University of Kentucky Coldstream Dairy. The HR Tag (SCR Engineers Ltd., Netanya, Israel) automatically collected neck activity and rumination data in 2-h increments. The IceQube (IceRobotics Ltd., South Queensferry, United Kingdom) automatically collected number of steps, lying time, standing time, number of transitions from standing to lying (lying bouts), and total motion, summed in 15-min increments. IceQube data were summed in 2-h increments to match HR Tag data. All behavioral data were collected for $14 \mathrm{~d}$ before the predicted calving date. Retrospective data analysis was performed using mixed linear models to examine behavioral changes by day in the $14 \mathrm{~d}$ before calving. Bihourly behavioral differences from baseline values over the $14 \mathrm{~d}$ before calving were also evaluated using mixed linear models. Changes in daily rumination time, total motion, lying time, and lying bouts occurred in the $14 \mathrm{~d}$ before calving. In the bihourly analysis, extreme values for all behaviors occurred in the final $24 \mathrm{~h}$, indicating that the monitored behaviors may be useful in calving prediction. To determine whether technologies were useful at predicting calving, random forest, linear discriminant analysis, and neural network machine-learning techniques were constructed and implemented using $\mathrm{R}$ version 3.1.0 ( $\mathrm{R}$ Foundation for Statistical Computing, Vienna, Austria). These methods were used on variables from each technology and all combined variables from both technologies. A neural network analysis that combined variables from both technologies at the daily level yielded $100.0 \%$ sen-

Received May 29, 2016.

Accepted March 26, 2017.

${ }^{1}$ Corresponding author: jbewley@uky.edu sitivity and $86.8 \%$ specificity. A neural network analysis that combined variables from both technologies in bihourly increments was used to identify 2 -h periods in the $8 \mathrm{~h}$ before calving with $82.8 \%$ sensitivity and $80.4 \%$ specificity. Changes in behavior and machine-learning alerts indicate that commercially marketed behavioral monitors may have calving prediction potential.

Key words: calving prediction, precision dairy monitoring technology, machine learning

\section{INTRODUCTION}

Parturition is an important period for both cows and their calves. Dystocia and calf mortality in this period can negatively affect farm economics and animal welfare (Mee, 2004). In the United States, $19 \%$ of primiparous and $11 \%$ of multiparous cows experience mild to severe dystocia at calving (USDA, 2010). Cows that labor more than 70 min past the appearance of the amniotic sac outside the vulva are at increased risk for dystocia (Schuenemann et al., 2011). Providing timely calving assistance may reduce the risk of dystocia, reduce the pain associated with assisted labor (Mainau and Manteca, 2011), and improve reproductive performance in the subsequent lactation (Bellows et al., 1988). Identifying laboring cattle allows managers to assist in cases of dystocia. Dairy producers currently use a combination of breeding records and visual cues to estimate calving time; however, even experienced personnel may not accurately detect all calvings, because perceptible behavioral and physiological changes do not occur for every cow or at a consistent time across calvings (Hofmann et al., 2006; Sendag et al., 2008).

Precision dairy monitoring technologies provide alternatives to the subjective observation and assessment of calving behaviors, and they represent an alternative approach for predicting calving time. To date, the application of precision technologies in calving detection has consisted primarily of maternal body-temperature monitors. Maternal body temperature has been shown to decrease approximately $48 \mathrm{~h}$ before calving (Lammoglia et al., 1997; Burfeind et al., 2011). Commer- 
cially marketed temperature monitors measure dairy cattle reticulorumen temperature, skin temperature, and vaginal temperature, but none have been validated for calving prediction. Monitors inserted in the vagina and expelled at the beginning of the second stage of labor also exist (Palombi et al., 2013), but these tools have also not been validated. As well, these technologies are costly, and to our knowledge, no economic research establishing their feasibility on dairy farms has been completed.

Validated measures of activity (Champion et al., 1997; Robert et al., 2009; Bikker et al., 2014), lying behavior (McGowan et al., 2007; Ledgerwood et al., 2010; Mattachini et al., 2013a; Borchers et al., 2016), and rumination (Schirmann et al., 2009; Bikker et al., 2014; Borchers et al., 2016) exist and may offer other options for calving prediction. As well, many of these technologies and the variables they monitor are already commonly used on dairy farms (Borchers and Bewley, 2015). Furthermore, dairy cows change feeding, rumination (Huzzey et al., 2005; Schirmann et al., 2013; Pahl et al., 2014), and lying behavior (Huzzey et al., 2005; Miedema et al., 2011; Jensen, 2012) as calving approaches, making technologies that measure these behaviors potentially useful tools for calving prediction. Some research has endeavored to predict calving events using these measures. Clark et al. (2015) used the SCR HR Tag (SCR Engineers, Ltd., Netanya, Israel) to monitor rumination behavior and predict calving events, achieving $70 \%$ sensitivity and $70 \%$ specificity in predicting the day of calving. Similarly, Ouellet et al. (2016) evaluated systems that monitored rumination time, vaginal temperature, and lying behaviors for their accuracy in calving prediction and found that a combination of these variables had a greater level of prediction accuracy than considering any of them alone (77\% sensitivity, $77 \%$ specificity).

Most algorithm development and usage implements elements of statistical process control (MacGregor and Kourti, 1995), requiring the use of trial and error and development of deviations from baseline values. A newer approach in event prediction is machine-learning event prediction. Most machine-learning research in the dairy sciences has been applied to mastitis and estrus detection (Firk et al., 2003; Cavero et al., 2008; Sun et al., 2010); no research has addressed its use in calving prediction. Additionally, to our knowledge, no commercial precision dairy monitoring technologies use machine-learning techniques to create alerts.

Before these technologies can be useful in calving prediction, research is needed to determine whether the behaviors measured (e.g., activity, rumination, and lying behavior) are highly sensitive and specific in de- tecting imminent calving. The objectives of this study were 2-fold: (1) to quantify activity, rumination, and lying behaviors before calving using 2 commercially available technologies and compare these behaviors to previous literature and (2) to determine the calving prediction efficacy of these technologies, both individually and in combination, using machine-learning prediction techniques. Cow-specific data commonly available from herd management software were also included in the prediction methods. We hypothesized that activity, rumination, and lying behaviors on the day of calving would differ from typical values. In the calving prediction analysis, we hypothesized that a combination of variables from both technologies would generate greater prediction accuracy with machine-learning methods than variables from either technology alone.

\section{MATERIALS AND METHODS}

Data were collected using 20 primiparous and 33 multiparous prepartum Holstein dairy cattle (mean \pm SD; gestation length $277.6 \pm 4.9 \mathrm{~d}$; parity $2.3 \pm 1.5)$ from September 2011 through May 2013 at the University of Kentucky Coldstream Dairy Facility (IACUC Protocol Number: 2010-0776). Beginning 30 d before the expected calving date, cows were moved to dry cow facilities and housed in a 9.15- $\times$ 21.34-m sawdustbedded pack with constant access to 3.64 ha of pasture. A TMR was delivered to the pen once per day.

Two technologies were fitted to each cow by $28 \mathrm{~d}$ before the predicted calving. After calving, data were reduced to include only the 2 wk before calving from each cow. The HR Tag (SCR Engineers Ltd.) was placed on the left side of the neck and automatically collected neck activity and rumination data in 2 -h periods using a 3 -axis accelerometer and a microphone with a microprocessor, respectively. The IceQube (IceRobotics Ltd., South Queensferry, UK) was attached to the left rear leg and automatically collected number of steps, time spent lying, time spent standing (inverse of time spent lying), number of transitions from standing to lying (lying bouts), and a proprietary total motion variable in 15 min periods using a 3 -axis accelerometer. Third-party technology variable validations have been completed for the HR Tag (Schirmann et al., 2009) and the IceQube (McGowan et al., 2007; Mattachini et al., 2013b; Borchers et al., 2016), and both technologies have been found to accurately monitor their respective variables.

Cows in the dry pen were monitored for signs of calving every $3 \mathrm{~h}$. Individual cows were monitored every 15 min after the first sign of labor was detected (e.g., the amniotic sac or calf feet became visible outside of 
the vulva). After laboring cows were identified, cows were separated into individual pens, preventing pasture access. For each calving, farm staff were instructed to record the calving date, the cow's parity, the time calving began, and the approximate time the calf was fully outside the cow. Eleven cows were assisted during labor, and these cows were included in all analyses. The need for assistance in the birthing process was assessed and provided at the farm manager's discretion, or according to the farm's standard operating procedure.

\section{Statistical Analysis}

To quantify changes in behavior before calving, neck activity and rumination data from the HR Tag, and number of steps, time spent lying, number of lying bouts, and total motion data from the IceQube, were used to create 2 data sets: calving behavior per day and per $2 \mathrm{~h}$ period. For daily and bihourly analyses, data were averaged in 24 -h periods relative to calving. For bihourly analysis, the time of calving was used to retrospectively generate cow-specific numbers of hours before calving in 2 -h periods. This analysis was performed on each variable to put all cows on the same timeline regardless of the time of day, similar to the methods of Schirmann et al. (2013).

A mixed linear model (MIXED procedure of SAS version 9.3; SAS Institute, Inc., Cary, NC) generated daily least squares means, with parity group (primiparous or multiparous) and day before calving ( $\mathrm{d}-1$ to -14) serving as categorical fixed effects. Cows served as repeated subjects for all variables, and an autoregressive covariance structure was used to account for the fact that multiple observations were being collected from subjects over time. All 2-way interactions were tested in daily models, and non-significant $(P \geq 0.05)$ interactions were removed using backward stepwise elimination. All main effects remained in final models, regardless of significance. Tukey's range test was used to identify significant differences between days before calving.

All bihourly data were adjusted similar to the methods of Jensen (2012). All 2-h periods were assigned a label (h -2 to -334$)$ for each behavior and cow. For every cow, the bihourly value minus the average for the same 2-h time of day for the previous $3 \mathrm{~d}$ (to account for differences in circadian patterns) was used to determine deviation from baseline values (Jensen, 2012). This procedure was applied to all variables individually (neck activity, rumination, number of steps, time spent lying, number of lying bouts, and total motion). Least squares means were calculated from these differences, with parity (primiparous or multiparous), time of day (0000 h to $2359 \mathrm{~h}$ in 2 -h periods), and bihourly period before calving ( -334 to -2 , in 2 -h periods) as fixed effects. Cows served as repeated subjects. All 2-way interactions were tested, and non-significant $(P \geq 0.05)$ interactions were removed using backward stepwise elimination. All main effects remained in final models, regardless of significance.

Residual plots were generated and inspected to assess normality and detect potential outliers for each analysis. Data transformations were performed to meet normal distribution for daily number of steps and total motion, as well as bihourly neck activity, total motion, and number of steps. A natural logarithm transformation was performed on these variables to meet residual normality assumptions for mixed linear models.

\section{Prediction Model Development}

Machine-learning techniques were applied to the data sets to predict calving time. The 3 machine-learning analysis techniques used for calving prediction were random forest, linear discriminant, and neural network analyses. The random forest method is based on decision-tree classification and develops a group of tree-structured classification models. Each tree contributes an opinion of how the data should be classified (Breiman, 2001; Bishop, 2006; Shahinfar et al., 2014). Linear discriminant analysis is similar to ANOVA and regression methods but uses a categorical dependent variable and several continuous independent variables (McLachlan, 2004; Wetcher-Hendricks, 2011). Neural networks imitate the structure and function of the human brain, simulating human intelligence, learning independently and quickly, adapting continuously, and applying inductive reasoning to process knowledge (Zahedi, 1991; Krieter et al., 2006). In animal sciences, neural networks are the most frequently used machinelearning method (Shahinfar et al., 2014).

All analyses were constructed and implemented using the caret package in $\mathrm{R}$ (version 3.1.0; $\mathrm{R}$ Foundation for Statistical Computing, Vienna, Austria). To make the prediction methods as applicable to actual calving situations as possible, prediction models were developed, with the intent that they would be sequentially performed. The day of calving would first be identified using daily calving behavior data. The 8 -h period immediately preceding calving would then be determined using the bihourly data from the day of calving. Separate random forest, linear discriminant, and neural network analyses were performed for the IceQube, the HR Tag, and a combination of variables from both technologies, for a total of 18 prediction models ( 3 technologies $\times 3$ analyses $\times 2$ periods predicted).

The data sets used in each model were prepared in the same way. A data subset consisting of $80 \%$ of obser- 
vations was used as a "training" set to generate prediction models. A leave-one-out cross-validation method was performed for each machine-learning method to develop training-phase models. The remaining $20 \%$ of observations were used as the "testing" subset to evaluate the performance of the models. During the testing phase, trained models were used to predict periods of interest. True positives, false positives, true negatives, and false negatives were calculated for each daily and bihourly period, and the sensitivity, specificity, positive predictive value, and negative predictive value were calculated to evaluate the performance of different machine-learning techniques and technology.

Daily Calving Prediction Models. For daily calving prediction, the predicted variable was the day before calving ( $\mathrm{d}-1$ to -14$)$. The ability of models to predict the day before calving was used as the outcome of interest, but all days were included in the model. Data were summed by day in a 24 -h format, from 0000 h through 2359 h. Day 0 was not considered in daily prediction models to exclude periods in which calving occurred and remove any incomplete time periods.

Data were presented to machine-learning techniques in 3 separate ways. Analyses were performed individually (using complete daily data from each technology) and combined (using complete daily and bihourly data from both technologies). For example, only cows with complete data for the IceQube were included in IceQube calving prediction models, and cows missing data from either technology or all data from both technologies were removed from the combined calving prediction models. For this reason, sample sizes differed by day relative to calving, because of missing data as a result of technology failure or data transfer error. From $\mathrm{d}-1$ to -14 prepartum, sample sizes ranged from 43 to 51 cows for the HR Tag. For the same period, sample sizes for the IceQube ranged from 43 to 53 . For the combined analysis, only instances of data available from each technology were analyzed $(\mathrm{n}=43$ to 51$)$. Data on parity and days until estimated calving date (from breeding records) were included in the daily prediction models. Variables measured by each technology were also included in their respective prediction models (IceQube models: number of steps, time spent lying, number of lying bouts, and total motion; HR Tag models: neck activity and rumination; combination models: all variables from both technologies). The IceQube also monitored standing time (the inverse of lying time). Standing time was a variable supplied by the technology, and all available variables were used in prediction models to simulate actual conditions.

Bihourly Calving Prediction Models. A 24-h backward moving average was calculated for each cow's behavior and 2-h period to account for differences in circadian patterns. Machine-learning techniques were applied to $22 \mathrm{~h}$ of backward moving averaged data before calving. The 2 -h period immediately preceding calving was excluded from analysis, because alerts would be generated after or at calving completion and would not be obtained in a timely manner for a producer to execute meaningful interventions. Behavioral data, parity, and time of day were used to predict each 2 -h period before calving (bihourly periods from -2 to -22 $\mathrm{h}$ before calving; 11 total time points). The variable of interest was the 2 -h period before calving (representing data from -2 to $-4 \mathrm{~h}$ before calving), but due to large variations in calving behavior, this period was extended to the 8 -h period before calving. Sensitivity, specificity, positive predictive value, and negative predictive value were calculated using combined true positives, false positives, true negatives, and false negatives from this 8 -h period (data from periods -2 to $-4,-4$ to -6 , -6 to -8 , and -8 to -10 ). Variables measured by each technology were also included in their respective prediction models (IceQube models: number of steps, time spent lying, number of lying bouts, and total motion; HR Tag models: neck activity and rumination; combination models: all variables from both technologies). Standing time was also added to models that included IceQube data, similar to the daily analyses.

\section{RESULTS}

\section{Interactions and Parity Effects on Behavior}

We found significant interactions between parity and day before calving ( $\mathrm{d}-1$ to -14 ) for daily lying time (Table $1 ; P=0.02$ ). We also found significant interactions for parity and $2 \mathrm{~h}$ period before calving for the difference in bihourly neck activity (Figure 1; $P=$ 0.03). Primiparous cows differed from multiparous cows in lying behavior and neck activity: primiparous cows lay less and became more active before calving.

\section{Behavioral Comparisons}

We observed differences between days before calving for rumination time, total motion, lying time, and lying bouts (Table 1). We found no differences for neck activity and number of steps between days before calving. Behavioral changes by 2 -h period for the $72 \mathrm{~h}$ before calving are shown in Figures 1a to 1f. In the $24 \mathrm{~h}$ before calving, all measured variables were significantly $(P<0.05)$ affected by 2 -h period, indicating an effect of time, and therefore stage of labor before calving, on differences in behavior. 
Table 1. Adjusted LSM ( \pm SE) from daily mixed models accounting for parity; $14 \mathrm{~d}$ of prepartum behavioral data in dairy cattle $(\mathrm{n}=53$ calvings)

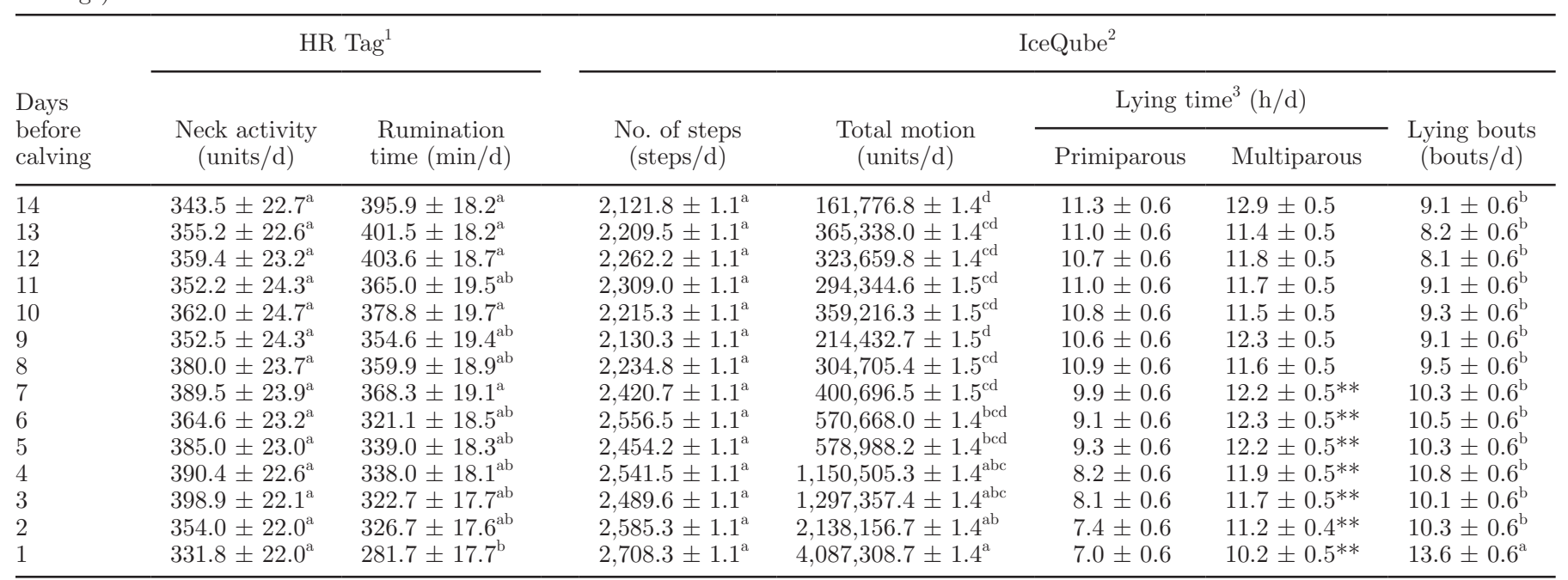

$\overline{\mathrm{a}-\mathrm{d}}$ Least squares means $\pm \mathrm{SE}$ within a column with different superscript letters differ $(P<0.05)$.

${ }^{1}$ SCR Engineers Ltd. (Netanya, Israel).

${ }^{2}$ IceQube sensor, IceRobotics Ltd. (South Queensferry, UK).

${ }^{3}$ A significant parity $\times$ day interaction was found for lying time. Lying time for primiparous and multiparous cows is reported.

**Least squares means $\pm \mathrm{SE}$ with asterisks indicate a significant day $\times$ parity interaction $(P<0.01)$.

\section{Activity Variables: Neck Activity, Number of Steps, Total Motion}

Neck activity and the number of steps taken were not different by day before calving (Table 1), but were affected by 2 -h period before calving (Table 1 ). Firstparity neck activity decreased to its lowest value $18 \mathrm{~h}$ before calving, and then increased to its highest value $2 \mathrm{~h}$ before calving. This indicates that these variables may not be useful for calving prediction at the daily level, but may be helpful at the 2 -h level.

\section{Rumination Behavior: Rumination Time}

Daily rumination time decreased throughout the prepartum period and was lowest on the day before calving (Table 1), but no differences were observed. Similarly, the baseline values in rumination at the 2 -h level were below baseline values for the entire $24 \mathrm{~h}$ before calving (Figure 1b). Rumination time decreased to its lowest value $8 \mathrm{~h}$ before calving. We observed an increase in rumination time beginning $8 \mathrm{~h}$ before calving, but values remained far below baseline values. This finding suggests that preparturient cows decrease rumination behavior as calving time approaches.

\section{Lying Behaviors: Lying Time and Lying Bouts}

Lying time decreased from $\mathrm{d}-14$ to -2 (Table 1). We found differences between parities for the final $7 \mathrm{~d}$ before calving. Lying times were least on the final day before calving for both parities (primiparous, 7.0 \pm 0.6 $\mathrm{h}$; multiparous, $10.2 \pm 0.5 \mathrm{~h}$ ). When we analyzed data for differences in 2-h intervals, we observed a similar trend in the $24 \mathrm{~h}$ to $48 \mathrm{~h}$ before calving (Figure 1e). The 2 -h periods throughout the $24 \mathrm{~h}$ preceding calving were variable for lying time, but lying time decreased to its lowest value $8 \mathrm{~h}$ before calving (a decrease of $34.7 \pm$ $9.3 \mathrm{~min}$ from baseline values). Lying time increased and exceeded baseline values $4 \mathrm{~h}$ before calving, indicating a return to normal behavior. This behavioral change indicates that although daily lying time decreased on the day of calving, cows lay more in the hours immediately preceding calving. Similarly, lying bouts increased on the day before calving (Table 1). Cows also steadily increased their lying bout frequency per 2-h period on the day of calving (Figure 1f).

\section{Machine-Learning Analyses}

The machine-learning methods used in this study produce results and output not typical of other prediction methods where algorithms are produced. The sample code and data are viewable at https://github. com/Mrborchers/Machine-learning-based-calving-prediction-from-activity-lying-and-rumination-behaviors. Prediction performance for daily methods is shown in Table 2. The ability to predict the day before calving was best when a combination of variables from the HR Tag and IceQube were used. We obtained the best daily 


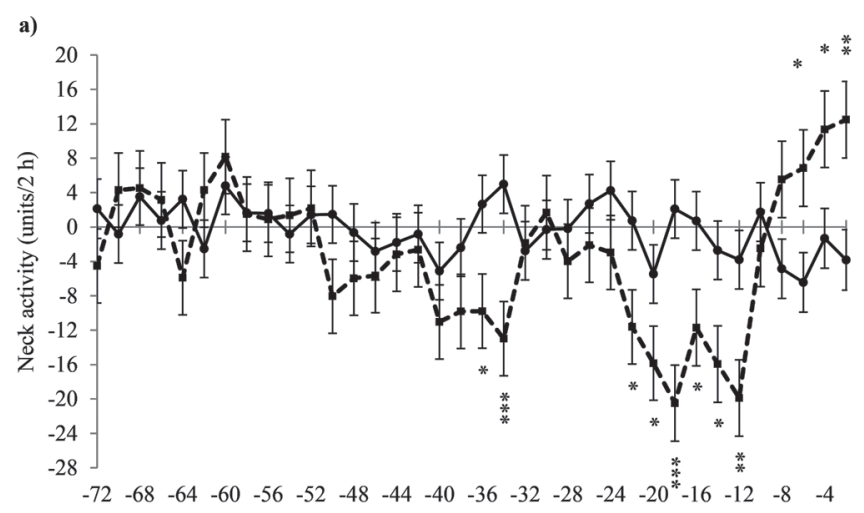

b)

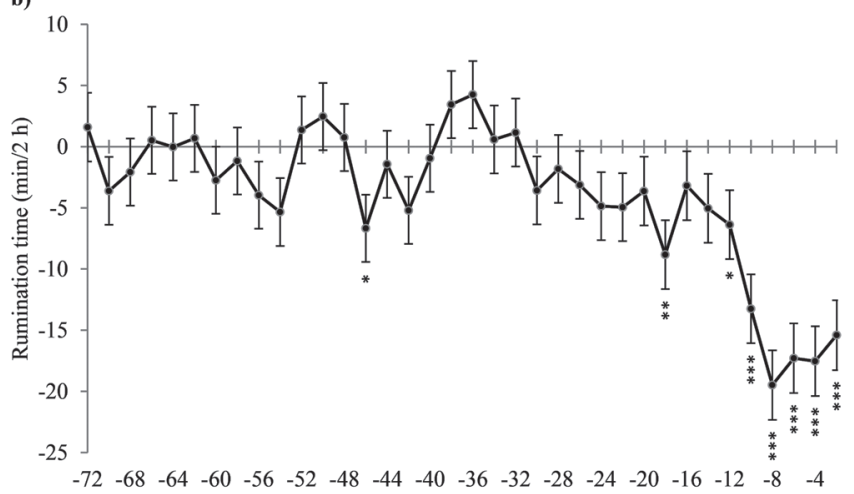

c)

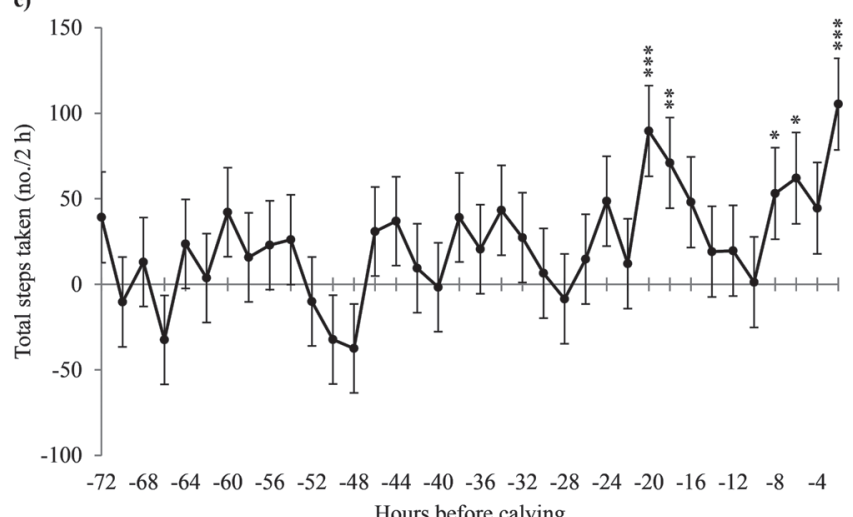

d)
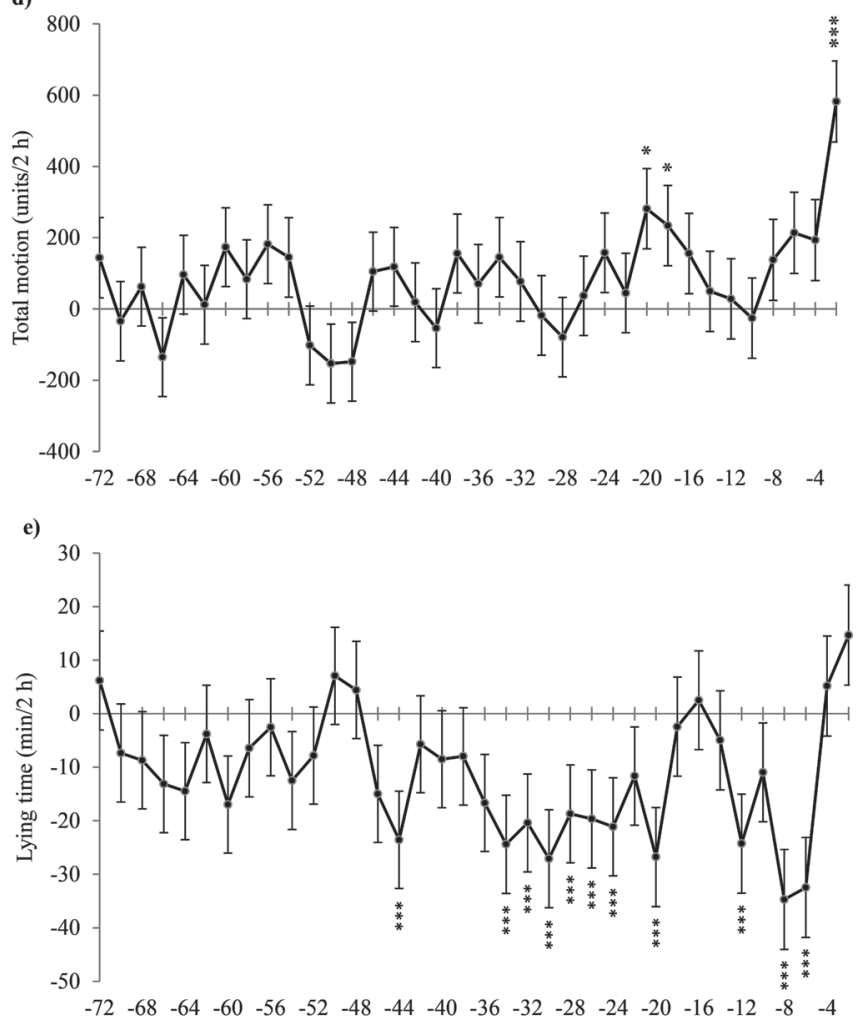

f)

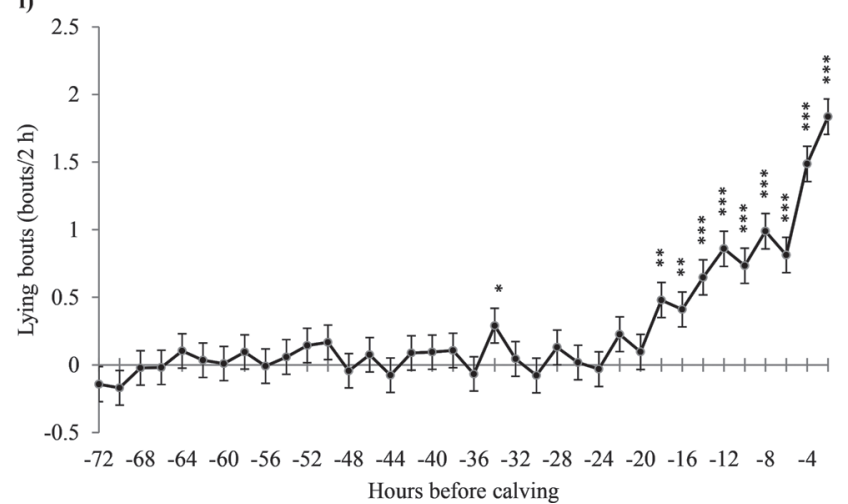

Figure 1. Behavioral differences expressed as LSM \pm SE in 2-h periods before calving for (a) neck activity (measured by the HR Tag; SCR Engineers Ltd., Netanya, Israel); (b) rumination time (measured by the HR Tag); (c) number of steps (measured by the IceQube sensor; IceRobotics Ltd., South Queensferry, UK); (d) total motion units (measured by the IceQube sensor); (e) lying time (measured by the IceQube sensor); and (f) lying bouts (measured by the IceQube sensor). Differences were calculated as each cow's 2-h behavioral data value minus the average of the same 2-h time of day for the previous $3 \mathrm{~d}$. A mixed linear model calculated LSM for $14 \mathrm{~d}$ of 2 -h data (72 $\mathrm{h}$ shown) of prepartum behavioral data $(\mathrm{n}=53$ calvings). A significant parity $\times$ day interaction was found for neck activity. Neck activity for primiparous (dashed line) and multiparous (solid line) cows is reported. ${ }^{*} P<0.05$, ${ }^{*} * P<0.01$, and $* * * P<0.001$ : significance for effects of 2 -h time points or effect of parity (in neck activity only) before calving on the deviation from baseline behavioral values.

calving prediction results in the combined variable neural network analysis.

The greatest sensitivity and specificity combinations were obtained when true positives, false positives, true negatives, and false negatives from the 2 -h periods from -2 to -8 (data from periods -2 to $-4,-4$ to $-6,-6$ to -8 , and -8 to -10$)$ were combined. These results are presented in Table 3. Similar to the daily analysis, neural network results for the bihourly combination analysis were the greatest.

Daily variable data measured by the IceQube sensor also effectively predicted the day of calvings in the lin- 
Table 2. Prediction of the day before calving ${ }^{1}$ using daily behavior data for $14 \mathrm{~d}$ before calving ${ }^{2}$

\begin{tabular}{|c|c|c|c|c|c|}
\hline Analysis & Technology ${ }^{3}$ & $\begin{array}{c}\text { Sensitivity } \\
(\%)\end{array}$ & $\begin{array}{l}\text { Specificity } \\
(\%)\end{array}$ & $\begin{array}{c}\text { Positive predictive } \\
\text { value }(\%)\end{array}$ & $\begin{array}{c}\text { Negative predictive } \\
\text { value }(\%)\end{array}$ \\
\hline \multirow[t]{2}{*}{ Random forest } & HR Tag & 12.5 & 95.6 & 20.0 & 92.6 \\
\hline & IceQube & 37.5 & 89.0 & 23.1 & 94.2 \\
\hline \multirow[t]{3}{*}{ Linear discriminant analysis } & HR Tag & 25.0 & 96.7 & 40.0 & 93.6 \\
\hline & IceQube & 75.0 & 91.2 & 42.9 & 97.6 \\
\hline & Combination & 75.0 & 93.4 & 50.0 & 97.7 \\
\hline Neural network & Combination & 100.0 & 86.8 & 40.0 & 100 \\
\hline
\end{tabular}

${ }^{1}$ The day of calving was excluded from daily machine-learning analyses.

${ }^{2}$ Machine-learning models were developed using leave-one-out cross-validation methods on $80 \%$ of observations. Models were then tested using $20 \%$ of observations $(\mathrm{n}=53$ calvings $)$. Sensitivity $=\mathrm{TP} /(\mathrm{TP}+\mathrm{FN}) \times 100 ;$ specificity $=\mathrm{TN} /(\mathrm{TN}+\mathrm{FP}) \times 100 ;$ positive predictive value $=$ $\mathrm{TP} /(\mathrm{TP}+\mathrm{FP}) \times 100$; negative predictive value $=\mathrm{TN} /(\mathrm{TN}+\mathrm{FN}) \times 100$; where $\mathrm{TP}=$ true positive, $\mathrm{TN}=$ true negative, $\mathrm{FP}=$ false positive, and $\mathrm{FN}=$ false negative.

${ }^{3}$ The HR Tag (SCR Engineers Ltd., Netanya, Israel) measured neck activity and rumination. The IceQube (IceRobotics Ltd., South Queensferry, UK) measured number of steps, total motion, lying time, and lying bouts. Variables from both the HR Tag and the IceQube were used in combination analyses.

ear discriminant analysis. We obtained similar results at the bihourly level, where the IceQube best identified the 8 -h period before calving compared with the HR Tag. The HR Tag alone was ineffective at the daily level, reaching the best prediction efficiency in the linear discriminant analysis. At the bihourly level, the HR Tag variables were best able to identify the 8 -h period before calving in the linear discriminant analysis.

\section{DISCUSSION}

\section{Behavioral Comparisons}

Primiparous cows showed differences in daily lying times or bihourly neck activity. Primiparous cow lying times decreased in the days before calving and were different from their multiparous counterparts beginning $7 \mathrm{~d}$ before calving. Lying time was least on the day of calving for both primiparous and multiparous cows. When separated by parity, neck activity may have use in calving prediction over shorter periods, and may be useful for predicting first-parity calvings. Similar to this study, Owens et al. (1985) and Wehrend et al. (2006) found that primiparous cattle became more restless before calving. This indicates that parity is important in describing the change in daily lying time and neck activity. Accordingly, we included parity in all prediction models.

Previous studies have shown that activity increases as calving approaches (Miedema et al., 2011; Jensen,

Table 3. Prediction of the 8-h period before calving on the day of calving (22-h data $)^{1}$ using 24 -h backward moving averaged 2 -h behavior data ${ }^{2}$

\begin{tabular}{|c|c|c|c|c|c|}
\hline Analysis & Technology ${ }^{3}$ & $\begin{array}{l}\text { Sensitivity } \\
(\%)\end{array}$ & $\begin{array}{l}\text { Specificity } \\
(\%)\end{array}$ & $\begin{array}{c}\text { Positive predictive } \\
\text { value }(\%)\end{array}$ & $\begin{array}{c}\text { Negative predictive } \\
\text { value }(\%)\end{array}$ \\
\hline \multirow[t]{2}{*}{ Random forest } & HR Tag & 72.4 & 89.3 & 77.8 & 86.2 \\
\hline & IceQube & 65.5 & 83.9 & 67.9 & 82.5 \\
\hline \multirow[t]{3}{*}{ Linear discriminant analysis } & HR Tag & 79.3 & 80.4 & 67.6 & 88.2 \\
\hline & IceQube & 72.4 & 78.6 & 63.6 & 84.6 \\
\hline & Combination & 75.9 & 75.0 & 61.1 & 85.7 \\
\hline Neural network & Combination & 82.8 & 80.4 & 68.6 & 90.0 \\
\hline
\end{tabular}

${ }^{1}$ The 2-h period immediately preceding calving was excluded from machine-learning analyses.

${ }^{2}$ Machine-learning models were developed using leave-one-out cross-validation methods on $80 \%$ of observations. Models were then tested using $20 \%$ of observations $(\mathrm{n}=53$ calvings $)$. Sensitivity $=\mathrm{TP} /(\mathrm{TP}+\mathrm{FN}) \times 100$; specificity $=\mathrm{TN} /(\mathrm{TN}+\mathrm{FP}) \times 100 ;$ positive predictive value $=$ $\mathrm{TP} /(\mathrm{TP}+\mathrm{FP}) \times 100$; negative predictive value $=\mathrm{TN} /(\mathrm{TN}+\mathrm{FN}) \times 100 ;$ where $\mathrm{TP}=$ true positive, $\mathrm{TN}=$ true negative, $\mathrm{FP}=$ false positive, and $\mathrm{FN}=$ false negative.

${ }^{3}$ The HR Tag (SCR Engineers Ltd., Netanya, Israel) measured neck activity and rumination. The IceQube (IceRobotics Ltd., South Queensferry, UK) measured number of steps, total motion, lying time, and lying bouts. Variables from both the HR Tag and the IceQube were used in combination analyses. 
2012), but their measurement of activity and methodology differed from the present study. For example, Miedema et al. (2011) used a within-cow comparison and observed that walking duration increased from control periods during the dry period to the $24 \mathrm{~h}$ before calving $(21.0 \pm 7.4$ vs. $31.5 \pm 13.1 \mathrm{~min} ; P<0.01)$. Similarly, Jensen (2012) observed an activity increase (calculated as acceleration not associated with gravity) beginning $6 \mathrm{~h}$ before calving $(F=5.46 ; P<0.01)$, compared with the same time of day in the $3 \mathrm{~d}$ before calving. These findings were similar to those for the total motion variable used in the present study, in which differences between days before calving were identified for the total motion variable. Total motion is a proprietary variable monitored by the IceQube, and the method by which it is calculated is not known. This variable may encompass all overall movements of the leg, as well as step number. This could include motions associated with lying and standing bouts and lateral movement, as well as steps. A variable analogous to lying bouts is standing bouts. Lying bouts and standing bouts would be approximately equivalent if measured individually. Standing bouts were not measured in this study but may be represented in total motion. The motions associated with a standing or lying event, if captured in total motion, would be potentially additive. This additive effect may have led to the overall total motion increase seen in this study.

For rumination behaviors, Clark et al. (2015) showed a $33 \%$ decrease in rumination time over the $2 \mathrm{~d}$ prepartum. In the present study, the same period showed a decrease of only 13\%. Similarly, Schirmann et al. (2013) observed a difference of $63 \pm 30 \mathrm{~min} / 24 \mathrm{~h}$ between the day of calving and a 2-d average rumination baseline value. We observed a 45-min difference in the present study between the day of calving and the day before. Ouellet et al. (2016) observed a 36-min decrease in this same period. In all studies, including the present study, a decrease in rumination was observed, but the magnitude of this decrease differed. Differences in environments and feedstuffs may explain these differences, but more research is needed.

In bihourly periods, rumination decreased by almost 20 min from baseline values $8 \mathrm{~h}$ before calving. Pahl et al. (2014) showed similar differences across two-hourly periods, but found the largest differences immediately preceding calving. The differences we found in rumination time (although not significant at the daily level) indicate that it may be a good predictor of calving across smaller periods immediately preceding calving. Although not significant, differences in rumination time may be useful in daily calving prediction models as well.
Jensen (2012) showed a gradual decrease in daily lying time from $16.6 \mathrm{~h} / \mathrm{d}$ on $\mathrm{d}-4$ before calving to 16.2 $\mathrm{h} / \mathrm{d}$ on $\mathrm{d}-2$ before calving. When data were analyzed by individual 2 -h periods in the $24 \mathrm{~h}$ before calving, Jensen (2012) found that lying time increased from $12 \mathrm{~h}$ before calving (31.4 $\mathrm{min}$ ) to $2 \mathrm{~h}$ before calving (42.8 $\mathrm{min}$ ). Cows remain recumbent during the second stage of labor as the calf moves through the birth canal (Schuenemann et al., 2011). These findings suggest that cows may become more uncomfortable and spend less time lying down during the few days before calving, but increase their lying time in the hours before calving as they begin labor.

Miedema et al. (2011) showed that lying bout frequency increased from the dry period to the $24 \mathrm{~h}$ before calving (16.4 \pm 4.8 vs. $24.2 \pm 6.8$ bouts per $24 \mathrm{~h}$ ). Beginning $18 \mathrm{~h}$ before calving in the present study, subsequent individual 2 -h periods significantly affected lying bouts. The greatest deviation from baseline values occurred in the $2 \mathrm{~h}$ immediately preceding calving (1.8 \pm 0.1 lying bouts). Over a similar period, Jensen (2012) showed that lying bouts per hour increased from 0.83 at $12 \mathrm{~h}$ before calving to 2.79 at $2 \mathrm{~h}$ before calving. The incremental increase in lying bouts and the changes in lying time indicate that dairy cattle may become restless in response to labor pain, but will remain recumbent longer for the final $4 \mathrm{~h}$ before calving.

Lying and rumination time are similarly correlated, with cows ruminating more frequently when lying down (Albright, 1993; Schirmann et al., 2012). Although lying time decreased $8 \mathrm{~h}$ before calving in the present study, it increased and surpassed baseline levels for the final $4 \mathrm{~h}$ before calving. However, the expected increase in rumination was not observed for this same period. This suggests an uncharacteristic change in normally correlated behaviors in the hours immediately preceding calving, which could be used in calving prediction models.

\section{Calving Prediction Methods}

The bihourly prediction method reported in this study was developed under the assumption that after identification of the day before calving, a test assessing behavior every $2 \mathrm{~h}$ could commence. A flaw with this approach is that if the daily analysis failed to identify the day before calving, the bihourly analysis would not begin. For example, a cow calving at $1030 \mathrm{~h}$ would have a day of calving alert at $0000 \mathrm{~h}$, and another alert identifying the $8 \mathrm{~h}$ before calving between $0200 \mathrm{~h}$ and 0959 $\mathrm{h}$ on that same day. We took this approach because fewer computations were required than examining all two-hourly data for all cows at each individual time 
point. This method accomplished the same goal of providing a timely alert without the need for numerous computations.

Calving prediction using a combination of automatically collected behavioral variables has previously been attempted. Maltz and Antler (2007) described calving prediction methods using changes in daily step number, lying behavior, and number of times passing into a feeding area for 12 cows over $7 \mathrm{~d}$ and achieved a sensitivity of $83.3 \%$ and a specificity of $95.2 \%$ in predicting the day of calving. Ouellet et al. (2016) also evaluated a combination of variables (rumination time, vaginal temperature, and lying behaviors) for their calving prediction accuracy and achieved $77 \%$ sensitivity, and $77 \%$ specificity. Similar to the present study, combinations of variables were most useful in calving prediction.

Although we observed favorable results in the current study, few technologies monitor rumination, lying behavior, and activity in combination. They commonly measure rumination and activity, or activity and lying behavior, but to our knowledge, few currently monitor all of these behaviors together. A 2-technology approach, such as that used in this study, could be useful for calving prediction, but would not be economically justifiable on commercial farms at present. In the absence of a 2-technology calving prediction approach, machine-learning techniques applied to technologies such as the IceQube may be the best option for behavior-based calving prediction.

Farm-specific algorithms using neural networks may be useful in creating accurate alerts, particularly during calving, because standard operating procedures vary between farms. Using data to train machine-learning techniques and create farm-specific prediction techniques could lead to more accurate and farm-specific event prediction, not only for calving prediction, but also for health status and estrus detection. Using technologies similar to the IceQube or HR Tag for calving prediction or applying machine-learning techniques to existing prediction techniques could provide additional uses for these technologies, increasing their perceived usefulness by producers and potentially their adoption (Borchers and Bewley, 2015).

Future work in calving event prediction will need to focus on the sensitivity and specificity of these technologies. In comparison to calving alerts, larger specificity values have traditionally been more valued in estrus and health because of the cost associated with missed events (ISO, 2007; Hogeveen et al., 2010; Rutten et al., 2013). In animal illness detection, false positives (type I errors) can cause financial losses through unnecessary treatment (Burfeind et al., 2011). These same principles are not as applicable in calving prediction. Identifying a non-laboring cow as calving could cause unnecessary treatment or handling. False negatives may be more costly with calving prediction, because systems do not detect actual calving events. The consequences of missed calving events could be extremely detrimental (e.g., dystocia, stillbirth, cow death) and may outweigh the comparative increase in farm labor from incorrectly identified calving events. Accordingly, calving prediction methods should be more sensitive and less specific if both factors cannot be concurrently obtained. Future research in calving prediction and economic modeling may need to explore this relationship more closely.

Additional benefits of calving prediction may be realized if calving alerts are generated from both large and small time intervals. Large intervals would allow dairy producers ample time to move cows to maternity pens if they choose, and closely monitor cows during labor to provide assistance as necessary. Advance knowledge of calving time would allow producers to provide high-risk cows with calcium supplements to reduce the risk of hypocalcemia after calving (Oetzel and Miller, 2012) or potentially reduce labor-associated pain by providing nonsteroidal anti-inflammatory drugs during calving (Newby et al., 2013).

Another use for calving prediction tools would be to distinguish between eutocial and dystocial calvings. Proudfoot et al. (2009) found that cows experiencing dystocia were more restless $24 \mathrm{~h}$ before calving than eutocial cows. Including calving ease evaluations in future machine-learning techniques may enable models to discern between dystocial and eutocial calvings. In the current study, farm staff did not record adequately specific calving ease indications, and these data were not included in machine-learning analyses. A follow-up study with a larger sample size is needed to determine whether cows experiencing dystocia can be identified using precision dairy monitoring technologies.

\section{CONCLUSIONS}

Precision dairy monitoring technologies, traditionally used for health and estrus alert generation, effectively quantified behavioral changes around calving. Application of calving prediction methods based on machine learning to these data was effective in performing retrospective calving prediction. Combining activity, rumination time, and lying behavior variables in neural network machine-learning methods generated sensitive and specific alerts at the daily and $8 \mathrm{~h}$ level. In the absence of rumination data, technologies monitoring only activity and lying behaviors could accurately predict the day and $8 \mathrm{~h}$ period before calving using neural network machine-learning techniques. Future work will 
need to identify calving events within smaller periods to provide alerts that farmers can use to make meaningful management decisions.

\section{ACKNOWLEDGMENTS}

The authors thank Joey Clark, Denise Ray, and the UK Coldstream Dairy Staff for collecting the calving data used in this study.

\section{REFERENCES}

Albright, J. L. 1993. Feeding behavior of dairy cattle. J. Dairy Sci. 76:485-498.

Bellows, R. A., R. E. Short, R. B. Staigmiller, and W. L. Milmine. 1988. Effects of induced parturition and early obstetrical assistance in beef cattle. J. Anim. Sci. 66:1073-1080.

Bikker, J. P., H. van Laar, P. Rump, J. Doorenbos, K. van Meurs, G. M. Griffioen, and J. Dijkstra. 2014. Technical note: Evaluation of an ear-attached movement sensor to record cow feeding behavior and activity. J. Dairy Sci. 97:2974-2979.

Bishop, C. M. 2006. Pattern recognition. Mach. Learn. 128:1-58.

Borchers, M. R., and J. M. Bewley. 2015. An assessment of producer precision dairy farming technology use, prepurchase considerations, and usefulness. J. Dairy Sci. 98:4198-4205.

Borchers, M. R., Y. M. Chang, I. C. Tsai, B. A. Wadsworth, and J. M. Bewley. 2016. A validation of technologies monitoring dairy cow feeding, ruminating, and lying behaviors. J. Dairy Sci. 99:74587466 .

Breiman, L. 2001. Random forests. Mach. Learn. 45:5-32.

Burfeind, O., V. S. Suthar, R. Voigtsberger, S. Bonk, and W. Heuwieser. 2011. Validity of prepartum changes in vaginal and rectal temperature to predict calving in dairy cows. J. Dairy Sci. 94:5053-5061.

Cavero, D., K. H. Tölle, C. Henze, C. Buxadé, and J. Krieter. 2008. Mastitis detection in dairy cows by application of neural networks. Livest. Sci. 114:280-286.

Champion, R. A., S. M. Rutter, and P. D. Penning. 1997. An automatic system to monitor lying, standing and walking behaviour of grazing animals. Appl. Anim. Behav. Sci. 54:291-305.

Clark, C., N. Lyons, L. Millapan, S. Talukder, G. Cronin, K. Kerrisk, and S. Garcia. 2015. Rumination and activity levels as predictors of calving for dairy cows. Animal 9:691-695.

Firk, R., E. Stamer, W. Junge, and J. Krieter. 2003. Improving oestrus detection by combination of activity measurements with information about previous oestrus cases. Livest. Prod. Sci. 82:97-103.

Hofmann, E., K. Failing, and A. Wehrend. 2006. Changes of the vulva and the vestibulum in suckler cows and heifers during the last seven days ante partum. Tieraerztliche Praxis Ausgabe Grosstiere Nutztiere 34:15-19.

Hogeveen, H., C. Kamphuis, W. Steeneveld, and H. Mollenhorst. 2010. Sensors and clinical mastitis - the quest for the perfect alert. Sensors (Basel) 10:7991-8009.

Huzzey, J. M., M. A. von Keyserlingk, and D. M. Weary. 2005. Changes in feeding, drinking, and standing behavior of dairy cows during the transition period. J. Dairy Sci. 88:2454-2461.

International Standards Organization. 2007. Automatic milking systems - requirements and testing. Annex C: Example of methods of evaluating detection systems for milk deemed as abnormal due to blood or changes in homogeneity. International Standards Organization, Geneva, Switzerland.

Jensen, M. B. 2012. Behaviour around the time of calving in dairy cows. Appl. Anim. Behav. Sci. 139:195-202.

Krieter, J., E. Stamer, and W. Junge. 2006. Control charts and neural networks for oestrus dectection in dairy cows. Pages 133-136 in Proc. GIL Jahrestagung, Potsdam, Germany. Gesellschaft für In- formatik in der Land- Forst- und Ernährungswirtschaft e.V., Göttingen, Germany.

Lammoglia, M. A., R. A. Bellows, R. E. Short, S. E. Bellows, E. G. Bighorn, J. S. Stevenson, and R. D. Randel. 1997. Body temperature and endocrine interactions before and after calving in beef cows. J. Anim. Sci. 75:2526-2534.

Ledgerwood, D. N., C. Winckler, and C. B. Tucker. 2010. Evaluation of data loggers, sampling intervals, and editing techniques for measuring the lying behavior of dairy cattle. J. Dairy Sci. 93:5129-5139.

MacGregor, J. F., and T. Kourti. 1995. Statistical process control of multivariate processes. Control Eng. Pract. 3:403-414.

Mainau, E., and X. Manteca. 2011. Pain and discomfort caused by parturition in cows and sows. Appl. Anim. Behav. Sci. 135:241-251.

Maltz, E., and A. Antler. 2007. A practical way to detect approaching calving of the dairy cow by a behaviour sensor. Pages 141-146 in Proc. Precision Livestock Farming. Wageningen Academic Publishers, Skiathos, Greece.

Mattachini, G., A. Antler, E. Riva, A. Arbel, and G. Provolo. 2013a. Automated measurement of lying behavior for monitoring the comfort and welfare of lactating dairy cows. Livest. Sci. 158:145-150.

Mattachini, G., E. Riva, C. Bisaglia, J. C. Pompe, and G. Provolo. 2013b. Methodology for quantifying the behavioral activity of dairy cows in freestall barns. J. Anim. Sci. 91:4899-4907.

McGowan, J., C. Burke, and J. Jago. 2007. Validation of a technology for objectively measuring behaviour in dairy cows and its application for oestrous detection. Page 136 in Proc. New Zealand Society of Animal Production. New Zealand Society of Animal Production, Dunedin.

McLachlan, G. 2004. Discriminant analysis and statistical pattern recognition. Vol. 544. John Wiley \& Sons, Inc., Hoboken, NJ.

Mee, J. F. 2004. Managing the dairy cow at calving time. Vet. Clin. North Am. Food Anim. Pract. 20:521-546.

Miedema, H. M., M. S. Cockram, C. M. Dwyer, and A. I. Macrae. 2011. Changes in the behaviour of dairy cows during the $24 \mathrm{~h}$ before normal calving compared with behaviour during late pregnancy. Appl. Anim. Behav. Sci. 131:8-14.

Newby, N. C., D. L. Pearl, S. J. Leblanc, K. E. Leslie, M. A. von Keyserlingk, and T. F. Duffield. 2013. Effects of meloxicam on milk production, behavior, and feed intake in dairy cows following assisted calving. J. Dairy Sci. 96:3682-3688.

Oetzel, G. R., and B. E. Miller. 2012. Effect of oral calcium bolus supplementation on early-lactation health and milk yield in commercial dairy herds. J. Dairy Sci. 95:7051-7065.

Ouellet, V., E. Vasseur, W. Heuwieser, O. Burfeind, X. Maldague, and E. Charbonneau. 2016. Evaluation of calving indicators measured by automated monitoring devices to predict the onset of calving in holstein dairy cows. J. Dairy Sci. 99:1539-1548.

Owens, J. L., T. N. Edey, B. M. Bindon, and L. R. Piper. 1985. Parturient behaviour and calf survival in a herd selected for twinning. Appl. Anim. Behav. Sci. 13:321-333.

Pahl, C., E. Hartung, A. Grothmann, K. Mahlkow-Nerge, and A. Haeussermann. 2014. Rumination activity of dairy cows in the 24 hours before and after calving. J. Dairy Sci. 97:6935-6941.

Palombi, C., M. Paolucci, G. Stradaioli, M. Corubolo, P. Pascolo, and M. Monaci. 2013. Evaluation of remote monitoring of parturition in dairy cattle as a new tool for calving management. BMC Vet. Res. 9:191.

Proudfoot, K. L., J. M. Huzzey, and M. A. von Keyserlingk. 2009. The effect of dystocia on the dry matter intake and behavior of Holstein cows. J. Dairy Sci. 92:4937-4944.

Robert, B., B. J. White, D. G. Renter, and R. L. Larson. 2009. Evaluation of three-dimensional accelerometers to monitor and classify behavior patterns in cattle. Comput. Electron. Agric. 67:80-84.

Rutten, C. J., A. G. Velthuis, W. Steeneveld, and H. Hogeveen. 2013 Invited review: Sensors to support health management on dairy farms. J. Dairy Sci. 96:1928-1952.

Schirmann, K., N. Chapinal, D. M. Weary, W. Heuwieser, and M. A. von Keyserlingk. 2012. Rumination and its relationship to feeding 
and lying behavior in Holstein dairy cows. J. Dairy Sci. 95:32123217.

Schirmann, K., N. Chapinal, D. M. Weary, L. Vickers, and M. A. von Keyserlingk. 2013. Short communication: Rumination and feeding behavior before and after calving in dairy cows. J. Dairy Sci. 96:7088-7092.

Schirmann, K., M. A. von Keyserlingk, D. M. Weary, D. M. Veira, and W. Heuwieser. 2009. Technical note: Validation of a system for monitoring rumination in dairy cows. J. Dairy Sci. 92:6052-6055.

Schuenemann, G. M., I. Nieto, S. Bas, K. N. Galvao, and J. Workman. 2011. Assessment of calving progress and reference times for obstetric intervention during dystocia in holstein dairy cows. J. Dairy Sci. 94:5494-5501.

Sendag, S., E. Hofmann, and A. Wehrend. 2008. Study about the occurrence of visible signs of approaching parturition in suckler cows and heifers: Changes of the udder. Dtsch. Tierarztl. Wochenschr. 115:66-70.

Shahinfar, S., D. Page, J. Guenther, V. Cabrera, P. Fricke, and K. Weigel. 2014. Prediction of insemination outcomes in Holstein dairy cattle using alternative machine learning algorithms. J. Dairy Sci. 97:731-742.

Sun, Z., S. Samarasinghe, and J. Jago. 2010. Detection of mastitis and its stage of progression by automatic milking systems using artificial neural networks. J. Dairy Res. 77:168-175.

US Department of Agriculture. 2010. Dairy 2007, Heifer Calf Health and Management Practices on US Dairy Operations, 2007. USDAAPHIS-VS-CEAH, Fort Collins, CO.

Wehrend, A., E. Hofmann, K. Failing, and H. Bostedt. 2006. Behaviour during the first stage of labour in cattle: Influence of parity and dystocia. Appl. Anim. Behav. Sci. 100:164-170.

Wetcher-Hendricks, D. 2011. Analyzing Quantitative Data: An Introduction for Social Researchers. John Wiley \& Sons, Inc., Hoboken, NJ.

Zahedi, F. 1991. An introduction to neural networks and a comparison with artificial intelligence and expert systems. Interfaces 21:25-38. 